\title{
LA PERSPECTIVA FEMINISTA EN LA EDUCACIÓN Y SUS DEBATES ACTUALES
}

\section{The Feminist Perspective in Education and its Current Debates}

\author{
María Rosa BUXARRAIS ESTRADA* y Sofía VALDIVIELSO GÓMEZ** \\ *Universitat de Barcelona. España. \\ mrbuxarrais@ub.edu \\ bttps://orcid.org/0000-0002-7511-3814 \\ * Universidad de las Palmas de Gran Canaria. España. \\ sofia.valdivielso@ulpgc.es \\ bttps://orcid.org/0000-0003-3826-5867
}

Fecha de recepción: 02/03/2021

Fecha de aceptación: 01/04/2021

Fecha de publicación en línea: 01/07/2021

Cómo citar este artículo: Buxarrais Estrada, M. ${ }^{a}$ R. y Valdivielso Gómez, S. (2021). La perspectiva feminista en la educación y sus debates actuales. Teoría de la Educación. Revista Interuniversitaria, 33(2), 129-147. https://doi.org/10.14201/teri.25923

\section{RESUMEN}

Estamos asistiendo a un debate social sobre el feminismo que está favoreciendo el resurgir de un pensamiento misógino muy antiguo. Las conquistas de las últimas décadas en relación con el avance de la igualdad entre los sexos se tergiversan y parece que el feminismo es responsable de desatar los instintos más bajos y el odio. Esto nos impide escuchar lo que realmente se está diciendo. Los pre-juicios nos lo impiden. El presente artículo profundiza en el desarrollo histórico del feminismo como teoría política y como praxis, examinando sus diferentes momentos desde la 
premodernidad hasta la posmodernidad. Se expone que el feminismo como teoría política y como movimiento social lleva ya más de tres siglos analizando la realidad y construyendo conocimiento imprescindible para entender las sociedades actuales y los debates que en ellas se están produciendo. En importante transmitir que el feminismo es un humanismo, que persigue la construcción de sociedades sustentadas en los valores de la igualdad, de la justicia y de la libertad. Para que esto sea posible es necesario incorporar la ética del cuidado en las aulas. Un cuidado que vaya de lo egocéntrico a lo mundicéntrico que nos incluya a todos y a todas y que trascienda lo humano para dar cabida también a la naturaleza y a todos los seres vivos. La educación que necesitamos debe dirigirse a la realización de valores universales básicos y a la construcción de sociedades más justas e inclusivas. Por ello es urgente darle más espacio y protagonismo en el sistema educativo y en el currículum.

Palabras clave: feminismo; educación; igualdad; ética; valores; ética del cuidado.

\section{ABSTRACT}

We are facing a social debate on feminism that is favoring the resurgence of very old misogynist thinking. The achievements of recent decades in relation to the advancement of equality between the sexes are being distorted and it seems that feminism is responsible for unleashing the baser instincts and hatred. This prevents us from listening to what is really being said. Prejudices prevent us from doing so. This article delves into the historical development of feminism as a political theory and praxis, examining its different moments from pre-modernity to post-modernity. It shows that feminism as a political theory and as a social movement has been analyzing reality for more than three centuries now and has built up knowledge that is essential for understanding today's societies and the debates that are taking place in them. It is important to convey that feminism is a humanism that seeks to build societies based on the values of equality, justice and freedom. For this to be possible, it is necessary to incorporate the ethics of care in the classroom. A care that goes from the egocentric to the world-centric, that includes all of us and that transcends the human to also include nature and all living beings. The education we need must be directed towards the realization of basic universal values and the construction of fairer and more inclusive societies. It is therefore urgent to give it more space and prominence in the education system and in the curriculum.

Key words: feminism; education; equality; ethics; values; ethics of care.

El trabajo de genealogía realizado por investigadoras feministas desvela que la desigualdad tiene raices muy profundas y muy antiguas. También desvela que los debates en torno al feminismo son recurrentes y aunque parecen nuevos, en realidad no son otra cosa que la actualización de debates muy antiguos que, en la 
mayoría de los casos, han girado en torno a las constelaciones de igualdad-libertad o naturaleza-cultura.

Consideramos que el feminismo es desde sus comienzos un humanismo pues ambos subrayan la urgente necesidad de educar a hombres y mujeres, como seres humanos iguales, en dignidad y derechos. Con este fin, muchas mujeres y hombres, están tomando medidas en todo el mundo para oponerse a los privilegios masculinos arbitrarios y a la violencia masculina (UNESCO, 2012).

Autoras como Amelia Valcárcel, Rosa Cobo, Ana de Miguel, Celia Amorós, Cristina Molina Alicia Miyares, Rosa María Rodríguez Magda, Alicia Puleo, y muchas más, han dedicado parte de su tiempo y de sus vidas a reflexionar sobre la igualdad ontológica entre hombres y mujeres. Se han centrado, sobre todo, en el análisis de los textos que dieron origen a las sociedades modernas con la intención de desvelar donde están las trampas por las que tres siglos más tarde del nacimiento del feminismo como teoría política, aún no hemos alcanzado la igualdad real. Esta indagación y disección profunda de los discursos emanados de las mentes masculinas de los últimos cinco siglos, ha convertido al Feminismo como Teoría política, en un impertinente (Varela, 2019). El feminismo es un discurso político que se basa en la justicia, es una teoría y una práctica política articulada por mujeres que, tras analizar la realidad en la que viven, toman conciencia de las discriminaciones que sufren por la única razón de ser mujeres y deciden organizarse para acabar con ellas. En este artículo tomaremos prestadas sus palabras y presentaremos las ideas que han sido claves en la reproducción de la desigualdad a través de todos los dispositivos sociales entre ellos la educación.

\section{LA POLÉMICA SOBRE LA IGUALDAD EN LAS SOCIEDADES PREMODERNAS}

En los siglos XVI y XVII (Cobo, 1995), el discurso hegemónico defendía que existía un orden natural de las cosas que era imposible alterar porque tenía un origen divino y ese orden no podía ser discutido, ni negado. Pero se hacía, aunque permaneciera oculto. De este período nos llegan dos discursos, por un lado, nos encontramos el discurso de la inferioridad y el de la excelencia y, por el otro, quienes defienden la igualdad ontológica entre los sexos.

El discurso de la inferioridad aplicado a las mujeres sostenía que éstas tenían una naturaleza y una ontología que era inferior a la de los varones. Por esta razón a las mujeres les corresponde ocupar los espacios secundarios y los inferiores. A este imaginario de la inferioridad se le aplicaba el discurso de la excelencia que partía de la idea de que las mujeres tenían un tipo de excelencia moral que no tenían los varones. Se las convencía de que ellas eran portadoras de esa excelencia moral que, para no contaminarla, necesariamente debía desembocar en la domesticidad. Ambos discursos perseguían convencer a las mujeres para que admitieran su inferioridad social. 
La supuesta inferioridad femenina es rebatida por mujeres letradas como Christine de Pizan. En su obra La ciudad de las damas (1405), la autora ataca el discurso de la inferioridad y hace una descripción detallada de todos los agravios que sufren las mujeres al no permitirseles participar de la vida pública. En ella encontramos ya un primer hilo que se desvincula de las teorías de la inferioridad pero no tiene la suficiente fuerza como para cambiar el orden establecido. Pero aunque no la tiene el debate continúa y dos siglos más tarde en 1673 Poulain de la Barre, filósofo de filiación cartesiana, publicó "La educación de los sexos" y en 1674 "De la educación de las Damas". Argumentaba que la desigualdad no se sustentaba en la naturaleza sino en el orden social basado en la autoridad del varón. Lo que hace este autor es invertir el argumento hegemónico y dice que no porque las mujeres sean inferiores tienen que ocuparse del marido, de la casa y de los niños, sino que como tienen que ocuparse de eso se hace necesario construir una teoría de la inferioridad para que la sociedad entera la asuma en su totalidad. En relación con la educación este autor rompe con la pedagogía medieval y exige la igualdad entre los sexos y también entre los estamentos y propone una estructura social que esté basada en un contrato social que garantice la igualdad y libertad de todas las personas, sin distinción de sexo ni de posición social.

Cuando el sistema estamental medieval se rompe dando paso a la ilustración y a la modernidad, se sientan las bases conceptuales del mundo actual. La ilustración abre el camino a la modernidad y a su sueño de alumbrar un mundo nuevo que esté presidido por dos principios éticos y políticos: la libertad y la Igualdad. Es en este contexto en el que la educación va a ser teorizada como una herramienta fundamental para el cambio social y como veremos a continuación sobre la igualdad o no entre los sexos, presentes ya en el medievo, también marcarán el debate en torno a la identidad y educación de los sexos en el periodo ilustrado.

\section{LA POLÉMICA CONTINÚA EN LA MODERNIDAD}

Rousseau se erige en uno de los pensadores más influyentes de la Ilustración. Dos de las obras escritas por este autor son relevantes para comprender el cambio social que se perseguía. El Emilio y el Contrato Social. Ambas obras fueron escritas de manera simultánea y la razón es que consideraba que la lectura de El Contrato Social serviría para producir cambios colectivos y El Emilio serviría para producir cambios en los individuos, de modo que lo individual y lo colectivo lo concebía y pensaba de forma complementaria. En lo referente al contrato social, Rousseau profundiza en la argumentación que de la Barre había realizado un siglo antes, pero en relación con la educación de las mujeres continua en la línea del pensamiento hegemónico del medievo basado en la inferioridad, aunque lo matiza y lo tiñe de trascendencia al considerar a las mujeres como «el ángel del hogar».

El Emilio es un tratado pedagógico que responde a qué educación es necesaria para la formación del nuevo ciudadano y cómo debe hacerse. El libro V lleva por 
título Sofía o la mujer, en él expone qué educación debe recibir cada sexo. Parte de la idea de que hombres y mujeres son ontológicamente diferentes, tienen naturalezas distintas y a través del análisis y descripción de estas diferencias establece las bases de la teoría de la complementariedad de los sexos que será hegemónica a lo largo del siglo XIX y parte del siglo XX. La ilustración sanciona que las mujeres son seres fundamentalmente domésticos y los varones lo son políticos y esto los lleva a afirmar que las mujeres deben ocupar el espacio privado-doméstico y los varones el público-político (Molina, 1994) y debido a ello es necesario que tengan educaciones distintas y en muchos aspectos contrapuesta. La educación de Sofía debe girar en torno a la castidad y a la modestia, a la domesticidad y a la sujeción al varón. Rousseau defiende que el destino de Sofía es la maternidad, el cuidado de sus hijos y «hacerle la vida agradable» al marido. Por su parte como el varón está obligado a proteger y a reconocer los hijos que ella pueda tener se justifica su autoridad sobre ella, como medio de asegurarse que esos hijos son suyos y no de otro.

Estas ideas generaron un importante debate social. Hombres como Diderot o Condorcet defendieron ideas basadas en el reconocimiento de la capacidad de razonar tanto de hombres como de mujeres y reprocharon a Rousseau su pensamiento fuertemente misógino y patriarcal. Las mujeres ilustradas se adscribieron a este discurso de la igualdad y defendieron la necesidad de educar en la igualdad política. Este debate pone de manifiesto que existieron otras voces que encontraron sus ecos en el medievo y se atrevieron a defender otra sociedad basada en la igualdad entre los sexos.

Las primeras obras consideradas fundacionales del feminismo son obras escritas por Olimpe De Gouge y Mary Wollstonecraft. Olympe de Gouges escribe la Declaración de los derechos de la mujer y de la ciudadana, aparecida en 1791. El texto, parelelo a la Declaración de los derechos del hombre y con el mismo número de artículos, denuncia la falsa universalidad de ésta al usar el término hombre con el significado real de varón y, al mismo tiempo, proclama explícitamente los mismos derechos para la mujer basándose en el principio de igualdad natural de todos los seres humanos.

Un año más tarde, en 1792, aparece Vindicación de los derechos de la mujer escrita por Mary Wollstonecraft. Esta autora, como los ilustrados más radicales, atribuye todas las desigualdades existentes a los prejuicios y a que estos están sólidamente anclados en los privilegios masculinos. Critica la idea de Sofía como metáfora y dirá de ella que es un modelo ideal de mujer que habita en la imaginación de Rousseau pero que carece de realidad ontológica y de realidad histórica. Wollstonecraft hace visibles todos los mandatos socializadores que colocan a las mujeres en una posición de inferioridad y desmonta los argumentos de los ilustrados misóginos demostrando que lo que se esconde detrás del discurso naturalista solo era una excusa para convencerlas de que su lugar "natural» y su "destino» era hacerse cargo de las tareas del cuidado de los hogares y de sus familias. 
Muchas mujeres no compartían estos mandatos y se organizaron, ocuparon las barricadas, montaron clubs culturales en los que se representaban obras de teatro escritas por mujeres y se les enseñaba a leer y a escribir, se les daban herramientas para mejorar en sus trabajos a aquellas que trabajaban en las fábricas en condiciones de extrema explotación y también a aquellas que eran prostituidas. Pelearon por los derechos de ciudadanía, por los derechos educativos y también por abolir la prostitución. Todo un despligue de solidaridad entre ellas que en el siguiente siglo servirá de modelo a las sufragistas. Ante la toma de conciencia de las mujeres como grupo (¡somos el tercer estado dentro del tercer estado! fue uno de sus lemas) el orden social patriarcal reaccionó violentamente, encerrándolas en los hogares, matándolas, encarcelándolas o metiéndolas en manicomios, por la única razón de haberse atrevido a poner en duda el orden social establecido.

Estos discursos ponen de manifiesto que no solo hubo una ilustración sino varias. Para el caso que nos ocupa resaltamos dos: una patriarcal y otra feminista. Rousseau es el representante de la ilustración patriarcal; Wollstonecraft, por su parte, lo es de la ilustración feminista.

La que terminó imponiendose fue la patriarcal y por ello, la ilustración, que en teoría representaba la promesa de liberación para todos y todas, se transforma en su opuesto, consumando y justificando la dominación y la sujeción de las mujeres, una vez definido lo 'femenino' por los hombres ilustrados, como naturaleza y como idéntico.

La teoría feminista establece el nacimiento del feminismo en estos años. Considera que tanto la Declaración de los derechos de la mujer y la ciudadana como la Vindicación de los derechos de la mujer, son las obras fundacionales del feminismo ilustrado en Europa. La Declaración de Seneca Fall (1848) se considera el documento fundacional del feminismo norteamericano.

A este periodo se le ha llamado primera ola del feminismo, pues se encargó de establecer las bases conceptuales de la igualdad política. Fue silenciada y sus herederas tuvieron que luchar durante más de ocho décadas para conseguir el reconocimiento de los derechos sociales y políticos.

El siglo XIX da paso a la segunda ola feminista que consitió en la organización política de las mujeres para conseguir el voto y los derechos educativos. Los argumentos para alcanzar la ciudadanía eran los mismos que las mujeres ilustradas habían elaborado para responder al discurso patriarcal de que eran naturaleza y su lugar era el especio privado

Esta segunda ola surgió en un entorno de industrialismo urbano. El objetivo de esta ola fue abrir oportunidades para las mujeres, centrándose en el sufragio y en los derechos educativos. Como era de esperar, contra las sufragistas aparecieron discursos y argumentos que pretendían convencer de la inferioridad natural de las mujeres. Los filósofos del XIX, argumentaron y publicaron sus explicaciones en torno a la incapacidad de las mujeres de ser deliberativas, de pensar y razonar por 
sí mismas. Ellos se encargaron de reforzar los argumentos del medievo en torno a la domesticidad de las mujeres.

Esta ola de vindicación del sufragio y de la educación fue creciendo a lo largo de todo el siglo XIX y concluyó en la primera mitad del siglo XX. Estuvo, en su mayoría, conformada por mujeres de la burguesía aunque también participaron muchas de la clase obrera. El movimiento consiguió el derecho al voto y los derechos educativos, y consiguió ambos en un periodo de ochenta años. A lo largo de este periodo las mujeres que se atrevieron a criticar el orden establecido por los hombres fueron ridiculizadas, humilladas, descalificadas, insultadas, agredidas, violadas y un largo etc., solo por reivindicar y exigir ejercer sus derechos de ciudadanía. Había que ser contundente para que sirviera de ejemplo a todas aquellas que observaban con simpatía este lucha. Es en este periodo cuando surge el concepto de feministas como un insulto. Pero lejos de amilanarse, las mujeres se apropiaron de él y comenzaron a llamarse feministas y toda la teoría política que se estaba desarrollando en torno a ellas pasó a llamarse Feminismo como concepto más amplio que Sufragismo, entendido como la lucha por el reconocimiento del sufragio. El feminismo le debe su nombre a esta reacción patriarcal para la que la prensa sirvió de altavoz.

El reconocimiento del derecho a voto y a una educación básica cierra la segunda ola y da paso a la tercera que se caracteriza por el surgimiento de diferentes corrientes teóricas que tratan de explicar la subordinación de las mujeres a los hombres.

\section{FEMINISMO LIBERAL}

Después del periodo bélico comienza un proceso, liderado por las fuerzas más conservadoras, dirigido a que las mujeres abandonen el espacio de lo público y regresen al espacio doméstico. Para hacer esto posible el hogar mismo debía renovarse y el papel femenino tradicional adecuarse al nuevo estado de cosas.

Mujeres con derechos ciudadanos recientemente adquiridos y una formación elemental o media, en número significativo, debían poder encontrar en el papel de ama de casa un destino confortable y libremente elegido. Los nuevos medios de comunicación de masas como la televisión y el cine se encargan de convencer a las mujeres de los años 50 para que libremente decidan quedarse en casa a cuidar de la familia. La idea de la complementariedad de los sexos vuelve a establecerse a través del amor romántico que se encarga de convencer a las mujeres de ideas que aun hoy se siguen consumiendo (el amor lo puede todo, somos complementarios, almas gemelas, medias naranjas y un largo etc.).

Este nuevo escenario de la "libre mujer moderna enamorada" debe verse como un conjunto de estrategias destinadas a mantener el sistema de dominación. Muchas lo asumieron e interiorizaron y volvieron al hogar, pero el ideal de la mujer moderna duró poco y comenzaron a enfermar de manera masiva. Betty Freidan comienza a analizar esta enfermedad sin nombre y en 1963 publica un libro que se convertirá en obra de referencia del feminismo liberal de posguerra. Bajo el título La mística 
de la feminidad analiza los discursos y presupuestos tradicionales acerca de la feminidad que obstaculiza el compromiso intelectual y la participación activa de las mujeres en su sociedad. Sin independencia económica, el modo de vida del ama de casa produce soledad, depresión y otros cuadros médicos calificados como "típicamente femeninos». Friedan analiza el sistema económico en el que se vende a las mujeres una identidad acorde con la unidad familiar de consumo en que se ha transformado la familia y las causas de esta depresión las coloca en la mística de la feminidad que volvía a implementar las ideas de la domesticidad como fuente de realización y de felicidad, el ángel del hogar había vuelto. Defiende la importancia de salir del hogar a trabajar y conquistar así su autonomía económica pero, no cuestiona el orden patriarcal.

En este período comienzan a construirse centros educativos de manera masiva. La educación se convierte en obligatoria y niños y niñas entran en el sistema. En las décadas de los 50 y 60 había centros para chicas y centros para chicos. La educación estaba segregada y, aunque había asignaturas específicas para unas y otros, en conjunto estudiaban el mismo currículum, un curriculum en el que el centro era el varón y su obra humana. De este modo, las niñas y las jóvenes estudiaron sin apenas referentes femeninos, porque las mujeres estaban fuera del curriculum oficial. En la década de los 70, los espacios se unifican y niños y niñas comparten las mismas aulas, pero las mujeres y sus aportaciones a la humanidad seguían fuera del curriculum oficial. En la escuela mixta ya no hay asignaturas específicas para las niñas, ahora todos y todas estudian lo mismo, aunque el curriculum seguía siendo fundamentalmente androcéntrico.

\section{FEMINISMO RADICAL}

La obra de Simone de Beauvoir El segundo sexo (Beauvoir, 1949), se convierte en un eje articulador entre el feminismo ilustrado y los nuevos feminismos, ya que posee una mirada retrospectiva y prospectiva. Según Celia Amorós y Ana de Miguel (2007) el punto retrospectivo dota de una fundamentación filosófica elaborada y consistente a las posiciones partidarias de la emancipación femenina dentro de los parámetros ilustrados, por otra, su deconstrucción de los mitos sobre la feminidad, anticipa lo que serán los temas propios del feminismo radical.

Las feministas radicales buscaron las respuestas en lo normativo no legislado - moral, modales y costumbre- demostrando que apenas había sufrido cambios. La idea de las feministas no solo giró en torno a subvertir el orden legal establecido, fue más allá, trastocando las costumbres y los modales. Ideas como la abolición del patriarcado y lo personal es político acentuaron los objetivos principales de esta corriente.

Otras dos obras se convierten en emblemáticas de este feminismo radical: Política sexual de Kate Millet (1963) y La dialéctica de la sexualidad de Shulamid Firestone (1970). El aporte fundamental de Millet, fue el haber introducido o relacionado la 
sexualidad con la política en el sentido de la distribución de poder que unos ejercen sobre otras y afirma que el sexo es una categoría social impregnada de política. Por su parte, Shulamith Firestone, a través de su obra la Dialéctica de la Sexualidad (1970), aportó uno de los lemas más significativos del feminismo radical lo Personal es Político explicando que todas las relaciones de dominación tienen su origen en el desigual poder entre los sexos en la organización familiar.

Estas dos obras fijaron los conceptos fundamentales para el análisis feminista como patriarcado, género y casta sexual. El género se conceptualiza como una categoria analítica que servíría para hacer visible cómo se distribuye el poder en la sociedad y cómo se construyen las identidades masculinas y femeninas a través de la socialización y la educación. Hace referencia a los aspectos culturales que se construyen a partir del sexo. La categoría género sirve para demostrar que nada de lo considerado natural, lo es y que la construcción de las identidades es un proceso que comienza en la infancia y se refuerza con la educación y la cultura.

En el plano educativo, los movimientos de renovación pedagógica feministas y sus investigaciones al interior del sistema educativo, desvelan cómo la escuela reproduce el orden social patriarcal a través de tres dispositivos: el curriculum explícito (solo se estudia la obra humana de los varones), el curriculum oculto (lo que no se enseña pero se aprende, relacionado con la transmisión de los mandatos de género), y el curriculum omitido (lo que no se enseña y no se aprende, p.ej., la ausencia de las aportaciones de las mujeres a la sociedad o la invisibilidad de las niñas a través del lenguaje). Para superar estas injustas desigualdades se propone la coeducación entendida como educar conjuntamente a niños y niñas en la idea de que hay distintas miradas y visiones del mundo, distintas aportaciones hechas por mujeres y por hombres que deben conformar la visión colectiva. La coeducación, como proceso intencionado de intervención, potencia el desarrollo de niñas y niños partiendo de la realidad de dos sexos diferentes hacia un desarrollo personal y una construcción social, comunes y no enfrentadas. Va encaminada al desarrollo de la personalidad sin barreras de género. (Simón, 2010).

Junto con todo lo anterior, las feministas radicales centraron su interés también en la sexualidad, desmarcándose así de las feministas liberales. Su principal idea ya no era lograr el espacio público, se hacía inminente transformar el espacio privado. Lo personal es político, logró que la teoría política ampliara sus horizontes en el sentido en que ésta pudo extenderse hasta las relaciones de poder que estructuraban la familia y la sexualidad. Tanto Firestone como Millet consideraban que los varones, todos los varones y no solo una élite, reciben beneficios económicos, sexuales y psicológicos del sistema patriarcal. (De Miguel, 2007)

Una vez conseguidas algunas de las demandas, el feminismo radical eclosiona, debido a la diferencia de objetivos en clave de sentido que la lucha feminista quería dar de ahora en adelante. Dicho planteamiento dio como resultado dos corrientes: el Feminismo de la Igualdad, llamado así porque ancla sus raíces en el discurso de 
MARÍA ROSA BUXARRAIS ESTRADA Y SOFÍA VALDIVIELSO GÓMEZ

LA PERSPECTIVA FEMINISTA EN LA EDUCACIÓN Y SUS DEBATES ACTUALES

la universalidad de los derechos, heredero de la Ilustración, y el Feminismo de la Diferencia, porque se separa de ese ideal pues estaba más anclado en las teorías posmodernas. Este debate abrió la puerta a los feminismos en plural.

\section{EL FEMINISMO DE LA IGUALDAD VS. DE LA DIFERENCIA}

El Feminismo de la Igualdad es heredero de la ilustración. De origen político liberal, radical, socialista materialista; su énfasis se halla en lo que une a las mujeres entre sí con el objetivo de introducir sus agendas en el proyecto común de la sociedad. Su aspiración final es poner fin a la imposición coactiva de las identidades y redefinir y subvertir la sociedad patriarcal en su lógica binaria de dominación. (Amorós y de Miguel, 2007).

El feminismo de la igualdad se expresa en clave vindicativa, en el sentido en que las mujeres deben tener los mismos derechos que los hombres; no menos ni otros, sino los mismos. Deben acceder a los mismos recursos, cobrar el mismo salario por el mismo trabajo y disfrutar de las mismas oportunidades, el mismo trato y las mismas condiciones.

Sin embargo, la idea de la universalización como norma que afecta a todos los sujetos no fue aceptada por todas las mujeres del movimiento feminista, pues afirmaban que esta idea, vista de esta manera, planteaba una mera integración en el mundo masculino sin cuestionarlo. Ésta última confrontación es acogida por un buen número de mujeres que ya se venían distanciando teóricamente; pues mientras que las teóricas de la igualdad bebían de las fuentes de la ilustración y de la modernidad; la otra parte del movimiento se alimentaba de las teorias posmodernas. Para ellas el discurso ilustrado se había quedado viejo y los autores posmodernos como Foucault, Deleuze y Guattari, Derrida, Chomsky y otros muchos estaban conceptualizando la realidad con otras categorías, que les eran más útiles para argumentar su discurso. No querían ni doctrinas ni doctrinarios. (Sendón, 2000).

Las defensoras de esta corriente feminista afirmaban que no querían ser iguales si no se cuestionaba el modelo social y cultural androcéntrico puesto que si no se hacía, la igualdad significaría el triunfo definitivo del paradigma androcéntrico (Sendón, 2000). Por ello definen el feminismo de la diferencia como una ética fundada en valores que las mujeres. Afirman que este feminismo no se opone al de la igualdad, que las mueve el mismo objetivo de transformar el mundo, aunque reconocen que su punto de partida tanto estratégico como epistemológico, radica en la diferencia sexual. Defienden que los cambios estructurales y legislativos pueden ser un punto de partida, pero no de llegada. Según esta perspectiva crear orden simbólico significa introducir la variable de la diferencia sexual en todos los ámbitos de la vida, del pensamiento, de la política. Para las partidarias de dicha corriente la solidaridad y complicidad entre las mujeres, es decir, la sororidad constituye el bagaje político más poderoso pues la lucha por el poder comienza en la 
autosignificación, la autoridad femenina y el empoderamiento de espacios creados por las propias mujeres.

Este discurso de la diferencia que, de manera indirecta vuelve recuperar la esencia femenina, abrió las puertas a otros feminismos como los coloniales que comenzaron a poner de manifiesto otro tipo de discriminaciones que afectaban a otras mujeres de otras clases sociales, etnias y culturas. Estas discriminaciones se expresaban no solo por el hecho de ser mujeres sino también por el hecho de ser negras, obreras, indias, lesbianas, etc.

\section{FEMINISMOS POSMODERNOS}

La posmodernidad rompe con el discurso universal y vuelve su mirada a las pequeñas historias, a las historias personales y subjetivas. Lo importante de pronto son los "márgenes». La otredad toma la escena y se genera una exigencia de reconocimiento identitario, que tenga en cuenta lo que hasta el momento se había dejado de lado, esto es, desigualdades basadas en los ejes: países ricos/pobres, hegemonía/periferia, heterosexualidad/homsexualidad etc. que según Nancy Fraser (1988) se potencian en un espacio público mundial. Tales tensiones contribuyen a la formación de nuevas identidades en permanente construcción.

En ésta nueva lógica aparecen distintas corrientes que utilizan la otredad y la identidad para sustentar sus reivindicaciones para ser visibles. Emparentados entre sí por un examen crítico de la lógica del domino, denuncian que se construye al "Otro o a la otra» o bien como proyección del sí mismo, o bien como otro jerárquicamente inferior.

Spivak (2011) con su obra "¿Puede hablar el subalterno?" responde que no, que no pueden hablar, en el sentido de que no son escuchados/as, porque su discurso no está validado por las instituciónes (educativas, médicas, jurídicas, científicas) que no solo se han encargado de silenciar sus voces, disciplinar sus cuerpos, sino de desechar la escucha y menospreciar sus saberes. Para Spivak, es imposible recuperar la voz de la mujer cuando a ella no le ha sido concedida una posición-de-sujeto desde la cual hablar. Recupera el concepto de subalterno, no en el sentido de oprimido; sino, en el de sin voz que no puede ser representado por nadie y que solo saldrá de su condición cuando sea escuchado, cuando tenga voz.

Todo lo anterior hace inminente darle voz a todas las mujeres que han estado silenciadas, y a quienes la construcción de un discurso propio les ha sido impuesto y negado. Por un lado, impuesto por las mismas mujeres que han tenido voz (blanca, europea, burguesa, y heterosexual). Es desde esta perspectiva desde donde se ha forjado el término «mujer», como si todas ostentaran las mismas características, las mismas condiciones, las mismas cosmogonías, y hubiesen construido el mundo de la vida con las mismas herramientas. Por otro lado, negado por los hombres de todas las condiciones y características. 
Con la idea de lo impuesto y lo negado se crea un abismo o una enorme ruptura de lo que se concibe con el término mujer, pues no es lo mismo ser una mujer negra pobre, que ser una mujer blanca europea adinerada. Por tales motivos no se debe hablar de la mujer sino de las mujeres, término más abarcativo que incluye a todas y que, a la vez, las recoge desde su singularidad. Visto así, se hace necesario recurrir a la interseccionalidad como una categoría que permita pegar los fragmentos revelando lo que no se ve cuando categorías como género y raza, por ejemplo, se conceptualizan como separadas unas de otras.

Los feminismos posmodernos se separan del feminismo de la igualdad en tanto que sostienen que las oposiciones binarias no resuelven todas las opciones de las mujeres. Sin embargo, tal y como afirma Amorós (2007) no se puede hablar de las identidades excluidas sin antes haber construido, de-construido y re-construido las identidades de mujeres y hombres. Porque según ella, es fundamental entender las diferencias para poder mirar la diversidad al interior del colectivo de mujeres. Es necesario poner el foco también en la estructura que nos construye como mujeres porque si no corremos el riesgo de perdernos en un bosque de fragmentos identitarios. El feminismo de la igualdad reconoce sus limitaciones al no haber tenido en cuenta la desigualdad al interior del colectivo de las mujeres. Las condiciones materiales de sus vidas y la experiencia del mundo son las que contribuyen a elaborar sus creencias y teorías a través de las cuales interpretan el mundo. Respetar las diferencias, tratando al sujeto de modo que se le represente como alguien socialmente situado en diversas posiciones de poder e identidad, siendo el género crucial y transversal en todas, se ha convertido en un proyecto filosófico importante para el feminismo.

\section{GENERISMO}

Precisamente el haber perdido el foco de la estructura que nos construye es lo que ha dado lugar al surgimiento de lo que Alicia Miyares (2019) ha conceptualizado como generismo que está desplazando el discurso de la iguadad por el de la identidad.

Desde sus comienzos el feminismo ha tenido claro que el sujeto político de sus luchas y reivindicaciones son las mujeres, entendiendo por tal a la hembra humana de la especie. Esto es un hecho y no se discute, lo que si se presta a discusión es el conjunto de significados culturales que se adscriben a esa hembra para que llegue a ser en una mujer. Las hembras siempre son las mismas, las mujeres cambian en función del contexto cultural en el que nacen.

Para el generismo todo es construcción social, nada hay fuera del relato. Por tanto el sexo también es una construcción y lo que es un hecho se convierte en una opinión. Judith Butler con publicaciones como El género en disputa (1990) o Deshacer el género (2006) sienta las bases epistemológicas de este nuevo discurso sobre las identidades. 
Este discurso ha salido de la academia y está colonizando las mentes de mucha gente que piensa que la identidad es algo subjetivo que nadie está autorizado a cuestionar. Para cimentar este discurso y que parezca que es muy profundo, se ha desarrollado una neolengua que quién no la utiliza o no la comparte se expone a ser señalada como fóbica o excluyente. Han aparecido conceptos nuevos como: queer, género fuido, identidad no binaria, cis-sexual, trans-sexual, bi-sexual, a-sexual, trans-género, despatologización, identidad de género, autodeterminación de género, persona gestante, persona menstruante, vientre de alquiler, etc. Se ha puesto el foco sobre el sujeto individual y es a él o a ella o a elle, a quién corresponde afirmar quién es y qué quiere y la sociedad debe aceptarlo sin discutirlo.

En el borrador de la Ley para la igualdad real y efectiva de las personas trans el sexo pasa a ser una asignación. Así en el artículo cuatro en el que se establecen las definiciones se dice:

A los efectos de esta ley, se entiende por: 1. Identidad de género o sexual: la vivencia interna e individual del género tal y como cada persona la siente y autodefine, pudiendo o no corresponder con el sexo asignado al nacer.

La plataforma educativa de Docentes Feministas por la Coeducación (DoFemCo), que entre sus fines está la difusión y reivindicación de la coeducación como una educación libre de sexismo y de androcentrismo, o la defensa de una enseñanza basada en hechos científicamente probados denuncia el impacto de la ley trans en las aulas. Esta ley que ahora se discute a nivel nacional viene precedida por otras leyes de identidad sexual aprobadas desde el 2012 en adelante en el conjunto de las CCAA.

Estas leyes obligan al profesorado y a los centros a aceptar y validar el autodiagnóstico del alumnado que no se identifica con su género, también a acompañar y afirmar el deseo del alumnado sin posibilidad de objetar, pues de hacerlo se expone a que se le acuse de transfobia y se le apliquen las correspondientes sanciones. Al profesorado de infantil y primaria se le pide que identifique, en base a criterios dados, y que el feminismo califica como sexistas, a potenciales alumnos o alumnas trans a partir de la observación. Así, en el protocolo de actuación aprobado por la Junta de Andalucía se dice textualmente:

Cuando el tutor o tutora de un grupo, /.../ observe que un alumno o una alumna menor de edad manifieste, de manera reiterada, actitudes de una identidad de género no coincidente con el sexo asignado al nacer, lo comunicará al equipo directivo del centro,... (Orden, 28 de abril 2015).

Esto está produciendo una gran confusión en los centros educativos.

Para concluir este punto nos gustaria resaltar que el feminismo como movimiento social y teoría política ha trabajado para abolir el género y para construir una realidad social formada por hombres y mujeres basada en la igualdad política, el reconocimiento de la diversidad y el respeto mutuo. Sin embargo, el patriarcado 
como orden social jerárquico ha trabajado en sentido contrario y ha pretendido borrar a las mujeres. En una primera fase las borraron adscribiendolas a la naturaleza y no reconociendolas como ciudadanas, en una segunda fase reconociéndolas como ciudadanas pero encerrándolas en los hogares. En una tercera fase igualándolas a los varones sin valorar sus diferencias. En la fase actual se persigue el mismo fin, se niega el sexo y se enfatiza el género como una identidad originaria. Este discurso está desplazando el discurso político de la igualdad por el de la diversidad identitaria y para ello vuelven a aparecer viejos argumentos basados en la naturaleza.

\section{8. ÉTICA DEL CUIDADo}

Ya hemos analizado cómo el feminismo, además de ser una lucha constante para eliminar la desigualdad entre hombres y mujeres también es una propuesta política para una sociedad democrática, fundada en un nuevo tipo de poder y convivencia humana, es decir, promueve una transformación radical de las estructuras sociales y la vida cotidiana en contra del patriarcado, que es el modelo de poder dominante, excluyente y limitador. Por eso, aparece este contrapoder, una nueva concepción del poder. Para ello necesita de una ética que le proporcione coherencia, «una ética es necesaria para darle sentido y dirección a los grandes procesos de cambio» (Camps, 1990).

Porque hasta el momento las mujeres han sido pensadas, habladas y representadas por los varones. Hay que crear un posicionamiento como mujeres desde un lugar de mujer, una conciencia nueva, para revertir lo que se ha adquirido como "natural", la minusvaloración de las mujeres. Debemos pensar en educar un nuevo sujeto político y un nuevo sujeto ético, el sujeto concreto, cotidiano, emocional y diverso.

La socialización se realiza de forma diferente en hombres y en mujeres. Tradicionalmente a lo femenino le asignamos el cuidado, lo personal, lo afectivo y la mediación. El cuidado se ha relacionado con la generación, reproducción, mantenimiento y conservación de la vida, tareas que históricamente han sido adjudicadas a las mujeres, a partir del rol de la maternidad, extendiéndolo a todos sus compartimientos sociales. Se identifica con una actitud maternal (Ruddick, 1986) de querer atender a las necesidades de los otros, lo que implica una responsabilidad social y no una mera elección individual, como un valor social transformador de la convivencia.

En este sentido, y considerando que la ética del cuidado supone un enfoque feminista de la educación, debe incorporarse a la pedagogía del siglo XXI.

En la ética del cuidado se reivindica la importancia de los sentimientos para la vida ética, moral. El pensamiento moral ilustrado y moderno es excesivamente racionalista, no ha reparado en el valor y la importancia del sentimiento y olvida, por lo tanto, no solo un aspecto importantísimo e irrenunciable de la sensibilidad humana, sino los 'motivos' para ser moral. [...] Si eliminamos el sentimiento del discurso moral, difícilmente 
conseguiremos un discurso motivador de la conducta, que es, a fin de cuentas, de lo que se trata (Camps, 1998, p. 74).

Con la ética del cuidado, se incorpora en la reflexión ética el otro como ser determinado, particular e histórico, y la relación de proximidad y afectiva como fundamento del comportamiento moral. La tradición filosófica occidental se ha centrado en la dimensión racional y ha olvidado también en exceso la dimensión sentimental, que es una dimensión fundamental para los seres humanos. No solo somos razón, sino también sentimiento.

La reflexión ética feminista sobre el cuidado tiene su origen en la obra de Carol Gilligan "In a Different Voice» (1982). Este texto revisa la presunta universalidad del paradigma evolutivo del desarrollo moral de Kohlberg (1976), quien con base en un estudio de 84 niños (todos varones) plantea una evolución que va desde la obediencia por temor al castigo en una primera etapa hasta la sexta considerada de madurez, en que las reglas se subordinan a principios universales de justicia (como el contrato social o los derechos naturales). En las conclusiones se señala que rara vez las mujeres pasan de la tercera etapa, y esto es considerado una deficiencia en el desarrollo moral característico de las niñas. Las únicas mujeres que alcanzan el sexto nivel -observa Kohlberg - son las educadas en universidades, sobre todo en la carrera de Derecho.

Kohlberg pensó en una evolución moral con tres estadios: $1^{\circ}$ ) Estadio preconvencional, en el que el sujeto conoce las reglas sociales, pero las considera como si fueran ajenas; $2^{\circ}$ ) Estadio convencional, en el que se produce una identificación y una interiorización de las reglas de las autoridades y $3^{\circ}$ ) Estadio postconvencional, que se caracteriza por el distanciamiento respecto de las reglas aceptadas y la definición de los propios valores y principios. Según esta perspectiva, el juicio moral maduro se hace en base a principios, analizando los problemas y situaciones a partir de una óptica universal.

Carol Gilligan (1985) presenta, en cambio, un modelo moral alternativo basado en el afecto y la filiación. Gilligan quiere demostrar que el accionar moral de las mujeres se centra en las relaciones afectivas y la responsabilidad más que en juicios generales abstractos. Esto debido a que su identidad estaría fuertemente constituida de manera relacional, con relación a un otro, llámese hija o hijo, padres, amistades, etcétera. La Ética del "cuidado» representó un cambio de paradigma que hasta entonces solo había escuchado la voz masculina:

Mientras hemos escuchado por centurias las voces de los hombres y las teorías del desarrollo que informan su experiencia, más recientemente hemos notado no solo el silencio de las mujeres sino también la dificultad de oír lo que dicen cuando hablan. Aún en la voz diferente de las mujeres descansa la verdad de una ética del cuidado, los lazos entre relaciones afectivas y responsabilidad y el origen de la agresión en el fracaso de la relación (Gilligan, 1982, p. 174). 
Se aporta una nueva experiencia y un giro conceptual en la visión ética, pero todavía faltará mucho por comprender porque se trata de oír voces desacostumbradas, de allí la dificultad teórica. La «otra voz» debe romper con el marco teórico a partir del cual se realiza la comprensión. Se plantea el dilema de pensar en términos de moralidad madura asociada a la racionalidad y universalidad, pautas masculinas de la ética. O escuchar la otra voz que propone tener en cuenta situaciones reales, evitar el daño, tener en cuenta las circunstancias y ante todo proteger. El trabajo de Gilligan demuestra que las mujeres elaboran de manera diferente las decisiones morales.

En general, las características de la ética del cuidado planteadas por Gilligan derivan de una concepción relacional, que:

- $\quad$ se caracteriza por un juicio más contextual y por una mayor tendencia a adoptar el punto de vista del "Otro particular", con sus peculiaridades; a la intervención de los sentimientos, la preocupación por los detalles concretos de la situación a juzgar.

- $\quad$ se basa en la responsabilidad por los demás, supone una preocupación por la posibilidad de omisión, de no ayudar cuando podríamos hacerlo. No se trata solo de contener la agresión, la falta de respuesta, también no actuar cuando habría que hacerlo, también malo.

- $\quad$ se basa en la comprensión del mundo como una red de relaciones, en las que se inserta el Yo.

- se ocupa no solo de las reglas, sino de cualquier cosa que se valore como moral. (Marín, 1993).

Desde la perspectiva de ética del cuidado, la interpelación del otro necesitado que exige ser atendido es clave como motor de la acción moral, la percepción y la empatía hacia el otro son condiciones de partida para toda práctica ética.

Algunas feministas como Celia Amorós, por ejemplo, alertaron contra la ética del cuidado y las consecuencias sacrificales que podría tener para las mujeres. Ella avisó «icuidado con la ética del cuidado! Porque todos los boletos de la rifa están en el bombo que nos corresponde a nosotras...». Una interpretación individualista del cuidado, tendería a crear dos mundos, el de la autonomía - patriarcal- y el mundo de las relaciones personales — en que se mantendría a las mujeres-.

Un claro peligro está en adoptar para el cuidado, la moral del esclavo, pérdida de autonomía, moral del sacrificio, porque tradicionalmente, las mujeres son las primeras suministradoras de cuidado y las últimas receptoras. Las mujeres del tercer mundo son cuidadoras del primer mundo... esto pone a prueba la solidaridad entre mujeres, alerta Celia Amorós. Y entonces, se hace evidente (como ya lo era en los '70) que gran parte de la liberación femenina no conflictiva de las mujeres de sectores acomodados, se basa en la explotación de mujeres pobres, y la igualdad y progreso conseguido por muchas europeas se levanta sobre los hombros y el trabajo de mujeres emigrantes. Entonces, cuando se miran muy de cerca los logros 
de la igualdad feminista, no son tantos. Es necesario introducir de forma efectiva la ética del cuidado en la educación, en el curriculum, en la cultura de la institución escolar como nos propone Noddings (2013).

El cuidado se propone como responsabilidad social y no mera elección individual. Se propone una ética del cuidado como un valor público para la construcción de ciudadanía. El norte del cambio ético será la construcción de una «sociedad del cuidado». En ella los miembros de la comunidad no solo deberían gozar de derechos, sino también asumir obligaciones por el bienestar colectivo. El interés por el cuidado de los otros, transformados en valores universales y, por tanto, esperables y deseables en el comportamiento de ambos géneros, es una premisa ética insoslayable para la generación de nuevos y mejores modelos de sociedad. Entendemos que se trata de complementar la justicia y el cuidado, superando la usual dicotomía masculino-femenino en el debate y asentada en una redefinición de la noción de justicia (Gozálvez y Jover, 2016). Held (2006) insiste en el valor del cuidado en la resolución de problemas políticos y globales, así como en asuntos cotidianos e interpersonales.

Sin duda quien mejor ha sabido captar las consecuencias del debate entre Kohlberg y Gilligan ha sido Benhabib, como nos recuerdan Gozálvez y Jover (2016). En este sentido, Benhabib se propone articular un nuevo universalismo, inclusivo en cuestión de género y basado en el reconocimiento de la otredad particular. Este universalismo interactivo es más próximo al desarrollo moral específico de las mujeres. De todas formas, puede aplicarse tanto a hombres como a mujeres, reconociendo así la pluralidad de modos del ser humano y diferencias como válidas moral y políticamente (cfr. Benhabib, 2006, p. 176).

Estamos de acuerdo en que los seres humanos vivimos en relaciones mutuas de cuidado: homines carens (Tronto, 2018) y a lo largo del siglo XX, el cuidado ha pasado del hogar al sector profesional, y debe también afianzarse en el sector educativo. Tronto (2013) subraya la importancia de una ética democrática del cuidado, es decir, entender la democracia como la asignación de responsabilidades entre todos los miembros de la comunidad política, así como el método democrático mediante el cual todas las personas tienen voz para dichas asignaciones. Pero sin un cambio significativo en la educación y la Pedagogía, la ética del cuidado se convierte en una utopía.

\section{REFERENCIAS BIBLIOGRÁFICAS}

Amorós, C. (1997). Tiempo de feminismo. Sobre feminismo, proyecto ilustrado y postmodernidad. Cátedra.

Amorós, C., y De Miguel, A. (Eds.). (2007). Teoría feminista: de la Ilustración a la Globalización (3 vols.). Minerva.

Beauvoir, S. de (1981). El segundo sexo. Aguilar. 
Benhabib, S. (2006). El ser y el otro en la ética contemporánea. Feminismo, comunitarismo y posmodernidad. Gedisa.

Butler, J. (2006). Deshacer el género. Paidós.

Butler, J. (2007). El género en disputa. Paidós.

Buxarrais, M. ${ }^{a}$ R., y Vilafranca, I. (2018). Una mirada femenina de la educación moral. Desclée de Brouwer.

Camps, M. V. (1990). Ética y democracia: una ética provisional para una democracia imperfecta. Revista del Centro de Estudios Constitucionales, 6, 25-35. https://dialnet.unirioja. es/servlet/articulo?codigo $=1050501$

Camps, M. V. (1998). Ciudadanía: derechos y deberes. Servicios sociales y política social, 41, 9-16. Cobo, R. (1995). Fundamentos del patriarcado moderno: Jean Jacques Rousseau. Cátedra.

Firestone, S. (1970). The dialect of Sex. The case for Feminism Revolution. Bantam Books.

Friedan, B. (2016). La mistica de la feminidad. Cátedra.

Fraser, N. (2008). Escalas de Justicia. Herder.

Gilligan, C. (1982). In a different voice: psychological theory and women's development. Harvard University Press.

Gilligan, C. (1985). La moral y la teoría psicológica del desarrollo femenino. FCE.

Gozálvez, V., y Jover, G. (2016). Articulación de la justicia y el cuidado en la educación moral: Del Universalismo sustitutivo a una ética situada de los derechos humanos. Educación XX1, 19(1), 311-330, https://doi.org/10.5944/educXX1.14221

Kohlberg, L. (1989). Estadios morales y moralización. El enfoque cognitivo-evolutivo. En E. Turiel, I. Enesco y J. Linaza (Comps.), El mundo social en la mente infantil (pp. 71-100). Alianza.

Kohlberg, L. (1992). Psicología del desarrollo moral. Descléee de Brouwer.

Marin, G. (1993). Ética de la justicia, ética del cuidado. Universitat de Girona. https://www. academia.edu/3242395/\%C3\%89tica_de_la_justicia_\%C3\%A9tica_del_cuidado

Millet, K. (1963). Política Sexual. Cátedra.

Miyares, A. (2021). Distopías patriarcales. Análisis Feminista del "generismo queer». Cátedra.

Molina, C. (2018). Dialéctica Feminista de la Ilustración. Tirant Humanidades. 2. ${ }^{a}$ ed.

Noddings, N. (2013). An Ethic of Caring and Its Implications for Instructional Arrangements. En B. J. Thayer-Bacon, L. Stone \& K. M. Sprecher (Eds.), Education feminism. Classic and Contemporary Readings (pp. 137-161). Suny Press.

Rodríguez, R. M. (2019). La mujer molesta. Feminismos postgéneros y transidentidad sexual. Ménades.

Rousseau, J. J. (1980). El Contrato social. Espasa-Calpe.

Rousseau, J. J. (1995). Emilio, o de la educación. Alianza.

Ruddick, S. (1980). Maternal Thinking. In M. Pearsall (Eds.), Women and Values (pp. 110-120). Wadsworth.

Simón, E. (2010). La igualdad también se aprende. Cuestión de coeducación. Narcea.

Spivak, G. (2011). ¿Puede hablar el subalterno? Akal.

Sendón de León, V. (2002). Marcar la diferencia. Icaria.

Tronto, J. C. (2013). Caring Democracy: Markets, Equality and Justice. NYU Press. 
Tronto, J. C. (2018). La democracia del cuidado como antídoto frente al neoliberalismo. En C. Domínguez, H. Kohlen. y J. C. Tronto (Comps.), El futuro del cuidado. Comprensión de la ética del cuidado y la práctica enfermera (pp. 7-20). Ediciones San Juan de Dios.

Unesco. (2012). Conference 21st Century: Towards the New Humanism. http://www.unesco. org/new/en/media-services/single-view/news/a_new_humanism_for_the_21st_century/

Valcárcel, A. (1991). Sexo y filosofía. Sobre mujer y poder. Anthropos.

Valcárcel. A. (2019). Ahora, Feminismo. Cuestiones candentes y frentes abiertos. Cátedra.

Valcárcel, A. (2000). La memoria colectiva y los retos del feminismo. En A. Valcárcel y R. Romero (Eds.), Los desafíos del feminismo ante el siglo XXI (pp. 19-54). Instituto Andaluz de la Mujer.

Varela, N. (2019). Feminismo para principiantes. Penguin Random House. 3. ${ }^{a}$ ed.

Wollstonecraft, M. (1998). Vindicación de los derechos de la mujer (Edición abreviada). Debate. 